\title{
SAVE LIFE SAVE PAKISTAN THROUGH PRIMARY PREVENTION BY RISK STRATIFICATION OF ATHEROSCLEROTIC CARDIOVASCULAR DISEASE
}

\begin{abstract}
Tariq Ashraf', Muhammad Ishaq Khan ${ }^{1}$, Musa Karim²
1 Karachi Institute of Heart Diseases, Karachi, Pakistan

2 National Institute of Cardiovascular

Diseases, Karachi, Pakistan

Address for Correspondence:

Dr. Tariq Ashraf

Professor of Cardiology, Karachi

Institute of Heart Diseases, Karachi,

Pakistan

Email: tariqash45@gmail.com

\section{Contribution}

TA conceived the idea of editorial, TA, MIK, and MK conducted literature review, and drafted manuscript.

Author declare no conflict of interest.

This article may be cited as: Ashraf $T$, Khan MI, Karim M. Save Life save Pakistan through Primary Prevention by Risk Stratification of Atherosclerotic Cardiovascular Disease. Pak Heart J 2020;53(04):283-284.

About one fourth of the world population, living in the South Asia region are at an increased risk of atherosclerotic cardiovascular diseases (ASCVD). ${ }^{1,2}$

Pakistan's population comprises of over 200 million inhabitants of the South Asian origin. According to a recent study, more than $30 \%$ of the Pakistani individuals were at high risk $(>7.5 \%)$ of 10 years of ASCVD event. Smoking, diabetes (type II), systemic hypertension, and high cholesterol were the most prevalent modifiable risk factors. ${ }^{3}$

Ten years risk assessment of ASCVD was done in Karachi (a city representing the whole of Pakistan because of multi ethnic composition) by offering pooled cohort equation and Astronaut Cardiovascular Health and Risk Modification (Astro-CHARM) risk calculators. ${ }^{3}$ Risk stratification in South Asian populations comparable with studies done in the US. ${ }^{1}$

The study done by Ashraf et al. ${ }^{4}$ showed an overall hypertension to be $45.6 \%$, diabetes mellitus $15.8 \%$, current smoker $14.25 \%$, family history of myocardial infarction $30.57 \%$. Regarding ethnic distribution to ethnicities of this population Urdu speaking were shown to have an increase trend for diabetes, smoking and family history of heart attack while hypertension in Pushtoons (Table 1). Regarding distribution of coronary artery calcium (CAC) score for various ethnicities, rate of moderate (100 to 399 Agatstan Units) and high ( $\geq 400$ Agatston Units) risk among Punjabis was $4 \%$ and $8 \%$ respectively, while, for Urdu speaking it was $7 \%$ and $2.3 \%$ respectively. ${ }^{5}$
\end{abstract}

https://doi.org/10.47144/phj.v53i $\underline{4.2030}$

Pak Heart J 2020 Vol. 53 (04): 283-284
The pairwise comparison of ten years risk of atherosclerotic cardiovascular disease (ASCVD) event by various ethnicities of Pakistan with Pooled Cohort Equation (PCE) and Astro-CHARM showed Urdu speaking at high risk and Sindhi at least risk. ${ }^{5}$

\section{What needs be done?}

1. Implementation of pooled cohort equation and Astro-CHARM in Pakistani population needs to be done through general practitioners. This can be done through pharmaceutical friends by involving all private and public institutions of the countries. This purpose can be achieved through delivering lecturers and demonstrations either by direct lecturers or usual social media i.e. Zoom meetings, webinars, etc. An app can be created for pooled and Astro-CHARM which can be installed in GPs mobile phone. After risk stratification, life style modification, use of statins will be delivered to the general public. All data assimilated will be analyzed and share with medical community for further preventive strategies. 
2. A major setback in the risk calculator is that the risk score for subjects under 40 years of age cannot be calculated. Pakistan population having cardiac events are mostly of young age group. ${ }^{6}$ To overcome this plan is to have a baseline estimation of risk using this calculator in young patients of mentioned age group. This young cohort will be followed through the same mechanism of risk stratification and follow up for 5 years.

Although ASCVD scoring system including PCE and Astro-CHARM may help in primary prevention of Pakistan population in identifying individuals at high risk. Through risk calculators need validation with similar cohorts in this population with appropriate changes as needed.

Table 1: Risk factors for atherosclerotic cardiovascular disease (ASCVD) in various ethnicities of Pakistan ${ }^{5}$

\begin{tabular}{|l|c|c|c|c|c|c|}
\hline & Sindhi & Punjabi & Balochi & Pushtoon & Urdu & Others \\
\hline Hypertension & $48.1 \%$ & $46 \%$ & $50 \%$ & $54.9 \%$ & $36.4 \%$ & $50 \%$ \\
\hline Diabetes & $3.7 \%$ & $12 \%$ & $20 \%$ & $19.7 \%$ & $20.2 \%$ & $15.3 \%$ \\
\hline $\begin{array}{l}\text { Currently } \\
\text { Smoke }\end{array}$ & $11.1 \%$ & $14 \%$ & $10 \%$ & $8.5 \%$ & $15.5 \%$ & $20.8 \%$ \\
\hline $\begin{array}{l}\text { Family History } \\
\text { of Heart Attack }\end{array}$ & $18.5 \%$ & $38 \%$ & $40 \%$ & $29.6 \%$ & $38 \%$ & $20.8 \%$ \\
\hline
\end{tabular}

\section{REFERENCES}

1. Volgman AS, Palaniappan LS, Aggarwal NT, Gupta M, Khandelwal A, Krishnan AV, et al. Atherosclerotic cardiovascular disease in South Asians in the United States: epidemiology, risk factors, and treatments: a scientific statement from the American Heart Association. Circulation. 2018;138(1):e1-34.

2. George J, Mathur R, Shah AD, PujadesRodriguez M, Denaxas S, Smeeth $L$, et al. Ethnicity and the first diagnosis of a wide range of cardiovascular diseases: Associations in a linked electronic health record cohort of 1 million patients. PloS One. 2017;12(6):e0178945.

3. Hassan K, Mohydin B, Fawwad A, Waris N, lqbal $S$, Jawaid $M$. Predicting the risk of atherosclerotic cardiovascular disease (ASCVD) in Pakistani population. Clin Epidemiol Glob Health. 2019;7(2):184-7.

4. Ashraf $\mathrm{T}$, Mengal MN, Muhammad AS, Tareen AK, Khan MN, Kazmi KA, et al. Ten years risk assessment of atherosclerotic cardiovascular disease using Astro-CHARM and pooled cohort equation in a south Asian sub-population. BMC Public Health. 2020;20(1):403.

5. Ashraf T, Nadeem A, Sarwar S, Karim M. Risk of Atherosclerotic Cardiovascular Diseases in various Ethnicities of Pakistan. Pakistan Journal of Medical Sciences. 2020;36(6):1158.

6. Batra MK, Rizvi NH, Sial JA, Saghir T, Karim M. Angiographic characteristics and in hospital outcome of young patients, age up to 40 versus more than 40 years undergoing primary percutaneous coronary intervention. J Pak Med Assoc. 2019;69(4):1307-11. 